\title{
The Prognostic Value of Immune Factors in the Tumor Microenvironment of Penile Squamous Cell Carcinoma
}

\begin{abstract}
Sarah Rosanne Ottenhof ${ }^{1}$, Rosa Sanne Djajadiningrat ${ }^{1,2}$, Helene Hoegsbro Thygesen ${ }^{3,4}$, Pamela Josephine Jakobs ${ }^{1}$, Katarzyna Jóźwiak ${ }^{5}$, Anne Marijne Heeren ${ }^{6}$, Jeroen de Jong ${ }^{7}$, Joyce Sanders ${ }^{7}$, Simon Horenblas ${ }^{1}$ and Ekaterina Straschimirova Jordanova ${ }^{6 *}$

${ }^{1}$ Department of Urology, Netherlands Cancer Institute, Amsterdam, Netherlands, ${ }^{2}$ Department of Urology, HagaZiekenhuis, Hague, Netherlands, ${ }^{3}$ Department of Biometrics, Netherlands Cancer Institute, Amsterdam, Netherlands, ${ }^{4}$ Statistics, Department of Conservation, Hamilton, New Zealand, ${ }^{5}$ Department of Epidemiology and Biostatistics, Netherlands Cancer Institute, Amsterdam, Netherlands, ${ }^{6}$ Center for Gynecologic Oncology Amsterdam (CGOA), VU University Medical Center, Amsterdam, Netherlands, ${ }^{7}$ Department of Pathology, Netherlands Cancer Institute, Amsterdam, Netherlands
\end{abstract}

\section{OPEN ACCESS}

Edited by:

Jason Roszik,

University of Texas MD Anderson Cancer Center, United States

Reviewed by:

Franz Rödel,

Universitätsklinikum Frankfurt,

Germany

Giuseppe Di Lorenzo, Azienda Ospedaliera Universitaria

Federico II, Italy

Deilson Elgui De Oliveira, Universidade Estadual Paulista Júlio de Mesquita Filho (UNESP), Brazil

*Correspondence: Ekaterina Straschimirova Jordanova e.jordanova@vumc.nl

Specialty section: This article was submitted to Cancer Immunity and Immunotherapy, a section of the journal Frontiers in Immunology

Received: 26 March 2018 Accepted: 18 May 2018

Published: 11 June 2018

Citation: Ottenhof SR, Djajadiningrat RS, Thygesen HH, Jakobs PJ, Jóźwiak K, Heeren AM, de Jong J, Sanders J,

Horenblas $S$ and Jordanova ES (2018) The Prognostic Value

of Immune Factors in the Tumor

Microenvironment of Penile

Squamous Cell Carcinoma.

Front. Immunol. 9:1253.

doi: $10.3389 /$ fimmu.2018.01253
The host's immune system plays a pivotal role in many tumor types, including squamous cell carcinomas (SCCs). We aim to identify immunological prognosticators for lymph node metastases (LNM) and disease-specific survival (DSS) in penile SCC. For this retrospective observational cohort study, penile SCC patients $(n=213)$ treated in the Netherlands Cancer Institute, were selected if sufficient formalin-fixed, paraffinembedded tumor material was available. Analysis included previously described highrisk human papilloma virus (hrHPV) status, immunohistochemical scores for classical and non-classical human leukocyte antigen (HLA) class I, programmed death ligand-1 (PD-L1) expression, and novel data on tumor-infiltrating macrophages and cytotoxic an regulatory T-cells. Clinicopathological characteristics and extended follow-up were also included. Regression analyses investigated relationships of the immune parameters with LNM and DSS. In the total cohort, diffuse PD-L1 tumor-cell expression, CD163+ macrophage infiltration, non-classical HLA class I upregulation, and low stromal CD8 ${ }^{+}$T-cell infiltration were all associated with LNM. In the multivariable model, only tumor PD-L1 expression remained a significant predictor for LNM (odds ratio (OR) 2.8, $p=0.05$ ). hrHPV negativity and diffuse PD-L1 tumor-cell expression were significantly associated with poor DSS and remained so upon correction for clinical parameters [hazard ratio (HR) 9.7, $p<0.01$ and HR 2.8, $p=0.03$ ]. The only immune factor with different expression in HPV+ and HPV- tumors was PD-L1, with higher PD-L1 expression in the latter $(p=0.03)$. In the HPV- cohort $(n=158)$, LNM were associated with diffuse PD-L1 tumor-cell expression, high intratumoral $\mathrm{CD}_{163^{+}}$macrophage infiltration, and low number of stromal $\mathrm{CD} 8^{+}$ T-cells. The first two parameters were also linked to DSS. In the multivariable regression model, diffuse PD-L1 expression remained significantly unfavorable for DSS (HR 5.0, $p<0.01)$. These results emphasize the complexity of the tumor microenvironment in penile cancer and point toward several possible immunotherapy targets. Here described immune factors can aid risk-stratification and should be evaluated in clinical immunotherapy studies to ultimately lead to patient tailored treatment.

Keywords: B7-H1, HPV, immune escape, microenvironment, penile cancer, programmed death ligand-1, squamous cell carcinoma, T-cells 


\section{INTRODUCTION}

Penile squamous cell carcinoma (SCC) is a rare disease with an incidence of less than $1 / 100,000$ in Western countries $(1,2)$. The prognosis for early stage penile cancer patients is good (5-year survival without lymphogenic spread is $96 \%$ ) but worsens gradually with presence of lymph node metastases $(\mathrm{LNM})(2,3)$. Surgery is the mainstay of penile cancer treatment, for both primary tumors and LNM. Only in advanced stages (e.g., pelvic lymph node involvement or irresectable disease) multimodal treatment is necessary, mostly in the form of neoadjuvant chemotherapy or adjuvant radiation (4).

In $20-50 \%$ of the patients, penile SCC is induced by a persistent infection with high-risk human papilloma virus (hrHPV) $(5,6)$. Diagnosis, treatment, and follow-up are the same for hrHPV-negative $\left(\mathrm{hrHPV}^{-}\right)$and hrHPV-positive $\left(\mathrm{hrHPV}^{+}\right)$ tumors (4). Nevertheless, patients with $\mathrm{hrHPV}^{+}$tumors have a better disease-specific survival (DSS) than patients with $\mathrm{hrHPV}^{-}$ tumors (5-year DSS of 96 vs. $82 \%$ respectively) (7).

The difference in patient outcomes between $\mathrm{hrHPV}^{+}$and non-virally induced penile cancer may be partially explained by different immune escape mechanisms (8-14). Surely, immunosuppressive and immunostimulating factors in the tumor microenvironment (TME) co-determine the course of disease in many different cancers, but relatively little is known about penile $\operatorname{SCC}(15,16)$.

For example, in head and neck squamous cell carcinomas (HNSCCs) higher levels of tumor-infiltrating immune cells in $\mathrm{hrHPV}^{+}$tumors are indicated as pivotal role players in a better response to standard therapy in comparison to $\mathrm{hrHPV}^{-}$tumors (17-19). This concerns high levels of intratumoral $\mathrm{CD}^{+}$and $\mathrm{CD}^{+}$T-lymphocytes but also antigen presenting cells such as myeloid dendritic cells (18-21). CD8 ${ }^{+}$cytotoxic T-cells are capable of immediate tumor-cell killing and therewith are the effectors of anti-tumor response (21). Regulatory T-cells (Tregs) are well known for their detrimental effect on the immune response $(10,12,22)$. However, associations of Tregs with clinical outcome remain controversial. High numbers of FoxP3 ${ }^{+}$Tregs were associated with early stage disease and better overall survival in HNSCC, but with adverse patient outcome in colorectal cancer and non-small-cell lung carcinoma (18, 23-25). Cytotoxic and Treg subpopulations have both been described as prognostic factors separately, as well as the ratio between the two $(15,19,20,26)$. An increased CD8/ FoxP3-ratio at diagnosis has been associated with responsiveness to immunotherapy in renal cancer and melanoma (15, 27-29). Tumor-infiltrating macrophages (TIM) are usually macrophages with an immunosuppressive M2-phenotype (30-32). These macrophages are marked by CD163 and are associated with T-cell response suppression, migration, and treatment evasion $(30,31)$. High $\mathrm{CD}_{163^{+}}$macrophage infiltration was associated with high disease stage and LNM in hrHPV ${ }^{+}$cervical cancer, and with poor survival in oral SCC $(32,33)$.

In penile cancer, various immune escape mechanisms in the TME have been studied (partly by our group) (8-14). In a multivariable analysis by Vassallo et al., presence of FoxP3-positive lymphocytes (presumably Tregs) was associated with poor disease free survival (10). In addition, a decreased CD8/FoxP3-ratio was associated with tumor progression during follow-up (12). Human leukocyte antigen (HLA) class I was assessed with immunohistochemical (IHC) staining on a tissue microarray (TMA). A prognostic role was only found for HLA-A expression that was associated with decreased overall survival (9). No differences in HLA expression were observed between $\mathrm{HPV}^{-}$and $\mathrm{HPV}^{+}$ tumors. Programmed death ligand-1 (PD-L1) expression was assessed in multiple studies, using different antibodies and techniques (10-14). $\mathrm{HPV}^{-}$penile cancer cells are more often PD-L1 ${ }^{+}$. Tumor-cell PD-L1-expression was associated with worse DSS and LNM, especially a diffuse expression of PD-L1 throughout the tumor fields $(11,13,14)$.

To compare the prognostic value of all these parameters, and to determine which factors have the strongest associations with patient outcomes, different factors from the TME should be evaluated in an integrative analysis. The aim of this study was to gain insight in the TME, and to identify possible associations between TME factors and LNM/DSS in patients with penile cancer.

In this retrospective observational cohort study, we investigated previously determined factors (HPV status, classical and non-classical HLA class I, and PD-L1 expression) in combination with novel data on tumor-infiltrating cytotoxic T-cells, Tregs, and M2-polarized macrophages $(7,9,11)$.

\section{MATERIALS AND METHODS}

\section{Study Population and Tissue Samples}

Between 2001 and 2009, 487 consecutive patients were diagnosed with penile SCC in the Netherlands Cancer Institute, Amsterdam. All were considered for inclusion, according to the following criteria. Exclusion criteria were non-invasive carcinoma, neoadjuvant non-surgical treatment, no tumor tissue available in our institutional biobank (mostly because of surgical removal elsewhere or treatment with laser ablation). Inclusion criterion was that sufficient archived tissue needed to be available in our institutional biobank. Sufficient archived formalin-fixed, paraffin-embedded (FFPE) material was available from 216 patients. All were staged and surgically treated in a standardized way (34). Clinical follow-up data were updated. Patients were usually clinically followed for 5 years, after that, patient status was sometimes available through municipal administration. This study was carried out with approval of the institutional medical ethical committee that considered this study not falling within the scope of the act of research involving human subjects, it was also approved by the translational research board of our institute.

Evaluation of the IHC stainings on $5 \mu \mathrm{m}$ sections was performed by two researchers (Rosa Sanne Djajadiningrat and Ekaterina Straschimirova Jordanova or Sarah Rosanne Ottenhof and Ekaterina Straschimirova Jordanova) and an experienced uropathologist (Jeroen de Jong). Three patients were excluded because a majority of the parameters could not be analyzed (e.g., no invasive tumor present in sample).

\section{hrHPV-Typing}

For protocols of hrHPV-typing, classical HLA, non-classical HLA, and PD-L1 IHC analyses, we refer to our previous reports 
$(7,9,11)$. In short, hrHPV status was determined on 212 tissue samples using $\mathrm{GP}^{+} / 6^{+} \mathrm{PCR}$ enzyme-immunoassay for 14 different HPV types (7).

\section{Immunohistochemistry}

A TMA of 168 samples was immunohistochemically analyzed for HLA class I expression with the following antibodies: HCA2 (HLA-A), HC10 (HLA-B/C; both provided by Prof. Neefjes of our institute), anti-beta-2-microglobulin ( $\beta 2 \mathrm{~m}$; DAKO, Denmark), MEM-E/02 (HLA-E; Bio-Rad, USA), and 4H84 (HLA-G; from BD Pharmingen, USA) (9). PD-L1 was determined on 213 wholemount sections using the E1L3N clone (Cell Signaling, USA) (11).

Whole-mount sections from 213 FFPE tissue blocks were immunohistochemically stained for CD8 (C8/144B, DAKO, Denmark), FoxP3 (236A/E7, AbCam, England), and CD163 (MRQ-26, Cell Marque, Rocklin, USA) using the Ventana protocol and autostainer with heat induced antigen retrieval. Details of different IHC stainings are summarized in Table S1 in Supplementary Material.

\section{Immunofluorescent Double Staining}

Twelve randomly selected cases (six hrHPV ${ }^{-}$and six hrHPV tumors) were double-stained with primary antibodies CD163 (10D6, NCL-CD163, Novocastra, Germany) and CD68 (514H12, MCA1815, Bio-Rad, UK). Secondary antibodies from Life Technologies, USA were used for detection. The slides were analyzed manually using a fully motorized digital imaging fluorescence microscope (Axiovert-200M, Germany). More details of these stainings can be found in Table S1 in Supplementary Material.

\section{Scoring Methods}

Human leukocyte antigen-A, HLA-B/C, and $\beta 2 \mathrm{~m}$ expression were scored in a semiquantitative way with the quality control system proposed by Ruiter et al. using intensity and percentage, resulting in three categories: negative, weak or positive $(9,35)$. A combined score of HLA-A, HLA-B/C, and $\beta 2 \mathrm{~m}$ grouped tumors into categories of classical HLA class I expression: normal expression (all three positive), complete downregulation (negative $\beta 2 \mathrm{~m}$ or negative HLA-A and HLA-B/C), and partial downregulation (other combinations). Although HLA-A was significant in previous multivariable analysis of this cohort, the total score of classical HLA was used for analysis because it had stronger associations with updated variables (comparative data not shown) (9). HLA-E and HLA-G were scored as absent/upregulated, and a combined score resulted in two groups: tumors into normal expression of non-classical HLA class I (both negative) and upregulation (one or both upregulated).

Only membranous staining of PD-L1 was scored. Percentage of positive cells was noted, cut-off for PD-L1 positivity of tumors was $\geq 1 \%$ of tumor cells $(11,12,36,37)$. For PD-L1 ${ }^{+}$tumors, the tumor expression pattern was scored as diffuse (throughout the tumor fields) or margin (predominantly at the tumor-stroma margin) (11). Immune cells in stroma were scored binary (negative or positive). PD-L1-positive TIM were identified by size, shape, end position (large, round, with dendrites, and in tumor fields) and were scored as present or absent (11).
For $\mathrm{CD}^{+}$and $\mathrm{FoxP}^{+}$T-cell infiltration analysis, in each sample three peripheral and three central tumor focus fields were randomly selected in Aperio ImageScope (Leica Biosystems, Solms, Germany) and magnified by $20 \times$. Each image (focus field) contained stroma and tumor fields. The number of positive pixels was determined with the semi-automatic computer program Image-J (NIH, Bethesda, MD, USA; http://rsb.info.nih.gov/ij/). Images were deconvoluted with a plug-in to the color red. By setting a threshold (at 180 for every image), the positive pixels were separated from the negative pixels. For every image tumor fields were digitally selected. The size of the total image area, tumor area and stromal area in pixels was noted, together with the number of positive pixels in these areas. The stromal values were calculated by subtracting the tumor area from the whole image area. In each tumor slide, the average number of positive pixels in the six focus fields was used for both CD8 and FoxP3 in tumor area and stromal area. T-cell ratios were calculated by dividing the $\mathrm{CD} 8^{+}$ pixels by $\mathrm{FoxP}^{+}$pixels.

Semiquantitative analysis of CD163 in tumor and stroma determined low/high infiltration of $\mathrm{CD} 63^{+}$cells. The 12 immunofluorescently stained samples (CD163/CD68) were qualitatively analyzed.

\section{Statistical Analysis}

High-risk human papilloma virus subgroups were compared with respect to clinicopathological, tumor and stroma characteristics using chi-square test, Fishers' exact test, and $t$-tests for independent samples. Also, Kaplan-Meier estimated survival curves were

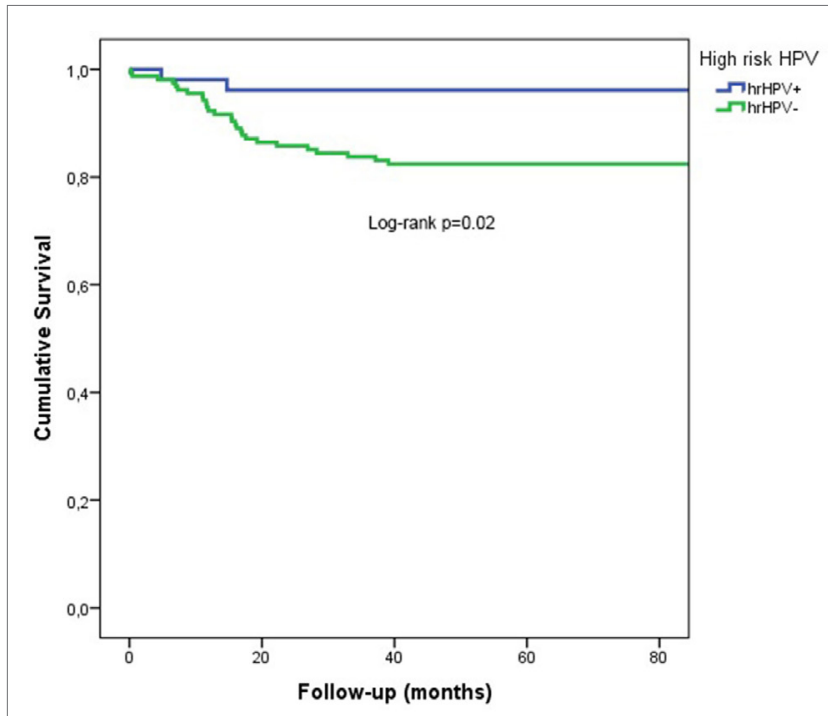

Number at risk:

\begin{tabular}{|c|c|c|c|c|c|c|}
\hline Baseline & 12 months & 24 months & 36 months & 48 months & 60 months & \\
\hline 52 & 52 & 49 & 48 & 48 & 45 & hrHPV $^{+}$ \\
\hline 158 & 142 & 130 & 142 & 121 & 115 & hrHPV $^{-}$ \\
\hline
\end{tabular}

FIGURE 1 | Kaplan-Meier survival plots with log-rank test analysis of high-risk HPV-positive and -negative penile cancer cases. 
plotted for HPV groups (Figure 1). Normality was assessed with Kolmogorov-Smirnov for all continuous parameters. T-cell parameters were transformed to log-scale to meet normality assumption when comparing means ( $t$-test). Pixel counts of CD8 and FoxP3 were divided by 100,000 for statistical analyses so that hazard ratios (HRs) and odds ratios (ORs) represent a substantial change. A constant integer (of 1) was added to stromal CD8 and stroma FoxP3 to prevent division by zero when calculating T-cell ratios. A logistic regression was used to model odds of LNM, and a Cox regression to model DSS from date of diagnosis to death from penile cancer or last follow-up/death from other cause. Characteristics that were significant or nearly significant in univariable models, were considered for final multivariable models found with a backward stepwise selection approach with models comparison using likelihood-ratio tests and $p>0.10$ as covariate exclusion criterion. All analyses were done using SPSS $^{\circledR}$ version 22 (IBM, Armonk, NY, USA) in collaboration with experienced statisticians (Helene Hoegsbro Thygesen and Katarzyna Jóźwiak).

\section{RESULTS}

\section{Clinicopathological Characteristics}

In this cohort $(n=213), 68$ patients $(31.9 \%)$ had LNM, and 87 patients (40.8\%) died during follow-up; 29 patients (13.6\%) died of penile cancer (on average after 14.7 months). Median overall follow-up was 100.7 months (IQR 69.4-119.7). Mean DSS was 166.8 months (median not reached).

Age was normally distributed. Tumor size was not. T-cell parameters (intratumoral and stroma CD8 and FoxP3, and T-cell ratios) were normally distributed after log-scale transformation. Clinicopathological characteristics are summarized in Table 1. When comparing the hrHPV subgroups with respect to these characteristics, we observed a significant difference only in differentiation grade $(p<0.01)$ and death by penile cancer $(p=0.02)$. Most well differentiated tumors were $\mathrm{hrHPV}^{-}$(70 vs. 9 in $\left.\mathrm{hrHPV}^{+}\right)$. Despite this, DSS was better in $\mathrm{hrHPV}^{+}$patients in comparison to $\mathrm{hrHPV}^{-}$patients, with 2 and 27 penile cancer

TABLE 1 | Clinicopathological characteristics.

\begin{tabular}{|c|c|c|c|c|}
\hline Variable & hrHPV $^{-}, N=158(\%)$ & hrHPV $^{+}, N=52(\%)$ & Total, $N=213(\%)^{a}$ & $p$-Value ${ }^{b}$ \\
\hline Age median (IQR) & $67.6(58.2-74.6)$ & $63.6(54.4-71.6)$ & $65.9(57.3-74.4)$ & 0.38 \\
\hline pT stage & & & & 0.17 \\
\hline pT1 & $42(26.6)$ & $19(36.5)$ & 61 (28.6) & \\
\hline pT2 & $99(62.7)$ & $28(53.8)$ & $130(61.0)$ & \\
\hline pT3 & $11(7.0)$ & 5 (9.6) & $16(7.5)$ & \\
\hline pT4 & $6(3.8)$ & - & $6(2.8)$ & \\
\hline Tumor size median (IQR) & $3.0(2.0-4.1)$ & $2.5(1.5-3.9)$ & $3.0(2.0-4.0)$ & 0.09 \\
\hline Histological subtype & & & & $0.08^{c}$ \\
\hline SCC NOS & $137(87.3)$ & $43(82.7)$ & $180(84.5)$ & \\
\hline Papillary & $8(5.1)$ & $1(1.9)$ & $9(4.2)$ & \\
\hline Verrucous & $5(3.2)$ & - & $5(2.3)$ & \\
\hline Warty & $2(1.3)$ & $3(5.8)$ & $5(2.3)$ & \\
\hline Basaloid & $1(0.6)$ & $4(7.7)$ & $5(2.3)$ & \\
\hline Mixed SCC-basaloid & $1(0.6)$ & $1(1.9)$ & $2(0.9)$ & \\
\hline Sarcomatoid & $1(0.6)$ & - & $1(0.5)$ & \\
\hline Cuniculatum & $1(0.6)$ & - & $1(0.5)$ & \\
\hline Pseudohyperplastic & $1(0.6)$ & - & $1(0.5)$ & \\
\hline Missing & $1(0.6)$ & - & $4(1.9)$ & \\
\hline Grade of differentiation & & & & $<0.01$ \\
\hline Well (grade 1) & $70(44.3)$ & 9 (17.3) & $80(37.6)$ & \\
\hline Intermediate (grade 2) & $62(39.2)$ & $31(59.6)$ & $94(44.1)$ & \\
\hline Poor (grade 3) & $26(16.5)$ & $12(23.1)$ & $38(17.8)$ & \\
\hline Missing & - & - & $1(0.5)$ & \\
\hline pN stage & & & & 0.84 \\
\hline pNO & $107(67.7)$ & $36(69.2)$ & $145(68.1)$ & \\
\hline $\mathrm{pN}+$ & 51 (32.3) & $16(30.8)$ & 68 (31.9) & \\
\hline Extranodal growth & & & & $0.12^{d}$ \\
\hline Present & $19(12.0)$ & $3(5.8)$ & $22(10.3)$ & \\
\hline Absent & $28(17.7)$ & $13(25)$ & $42(19.7)$ & \\
\hline No LNM & $107(67.7)$ & $36(69.2)$ & $145(68.1)$ & \\
\hline Missing & $4(2.5)$ & - & $4(1.9)$ & \\
\hline Death by penile cancer & & & & 0.02 \\
\hline No & $131(82.9)$ & $50(96.2)$ & 184 & \\
\hline Yes & $27(17.1)$ & 2 (3.8) & 29 & \\
\hline
\end{tabular}

IQR, interquartile range (25th-75th percentile); SCC, squamous cell carcinoma; NOS, not otherwise specified; HPV, human papilloma virus; LNM, Iymph node metastases. alncluding three cases with unknown hrHPV status.

${ }^{b}$ Excluding missing cases. Comparing the two hrHPV subgroups. Independent sample t-test for continuous variables, chi-square, or Fishers exact test for categorical variables. 'Divided in SCC NOS, unfavorable subtypes (basaloid, mixed basaloid-warty, and sarcomatoid) and favorable subtypes (papillary, verrucous, warty, cuniculatum, and pseudohyperplastic). ¿Excluding patients with no LNM/unknown lymph node status.

Bold numbers are statistically significant. 
related deaths, respectively $(\log -\operatorname{rank} p=0.02$; Figure 1$)$ at mean follow-up of 169.5 vs. 160.5 months. Among hrHPV ${ }^{+}$tumors, HPV16 was the predominant type 79\% (41/52) (7).

\section{Classical and Non-Classical HLA Expression and PD-L1 Expression Patterns}

Immune characteristics are summarized in Figure 2 and Table S2 in Supplementary Material. Aberrant classical and non-classical HLA expression was equally distributed among hrHPV ${ }^{-}$subgroups. Interestingly, $\mathrm{hrHPV}^{-}$tumors were significantly more often PD-L1 ${ }^{+}$( 49.4 vs. $32.7 \%$ of $\mathrm{hrHPV}^{+} ; p=0.03$ ). Also, there was a trend toward $\mathrm{hrHPV}^{-}$tumors having relatively more of both PD-L1 expression patterns compared with $\mathrm{hrHPV}^{+}$tumors $(p=0.09)(11)$.

\section{Tumor-Infiltrating Cytotoxic T-Cells and Tregs}

The presence of $\mathrm{CD}^{+}{ }^{+} \mathrm{T}$-cells and $\mathrm{FoxP}^{+}$Tregs was determined by standard IHC staining. Representative examples of CD8 and Foxp3 presence are depicted in Figures 3A-D. Interestingly, CD8 and FoxP3 pixel counts were much higher in stromal areas than in tumor areas, in both $\mathrm{hrHPV}^{-}$and $\mathrm{hrHPV}^{+}$tumors (Figure 2). No differences in T-cell numbers or CD8/FoxP3-ratio were found between $\mathrm{hrHPV}^{+}$and $\mathrm{hrHPV}^{-}$tumors (Figure 2; Table S2 in Supplementary Material).

\section{Tumor-Infiltrating Macrophages}

Representative examples of CD163 IHC stainings are depicted in Figures 3E,F. No significant differences in $\mathrm{CD}_{163^{+}}$macrophage intratumoral or stromal infiltration were observed between $\mathrm{hrHPV}^{-}$and $\mathrm{hrHPV}^{+}$samples.

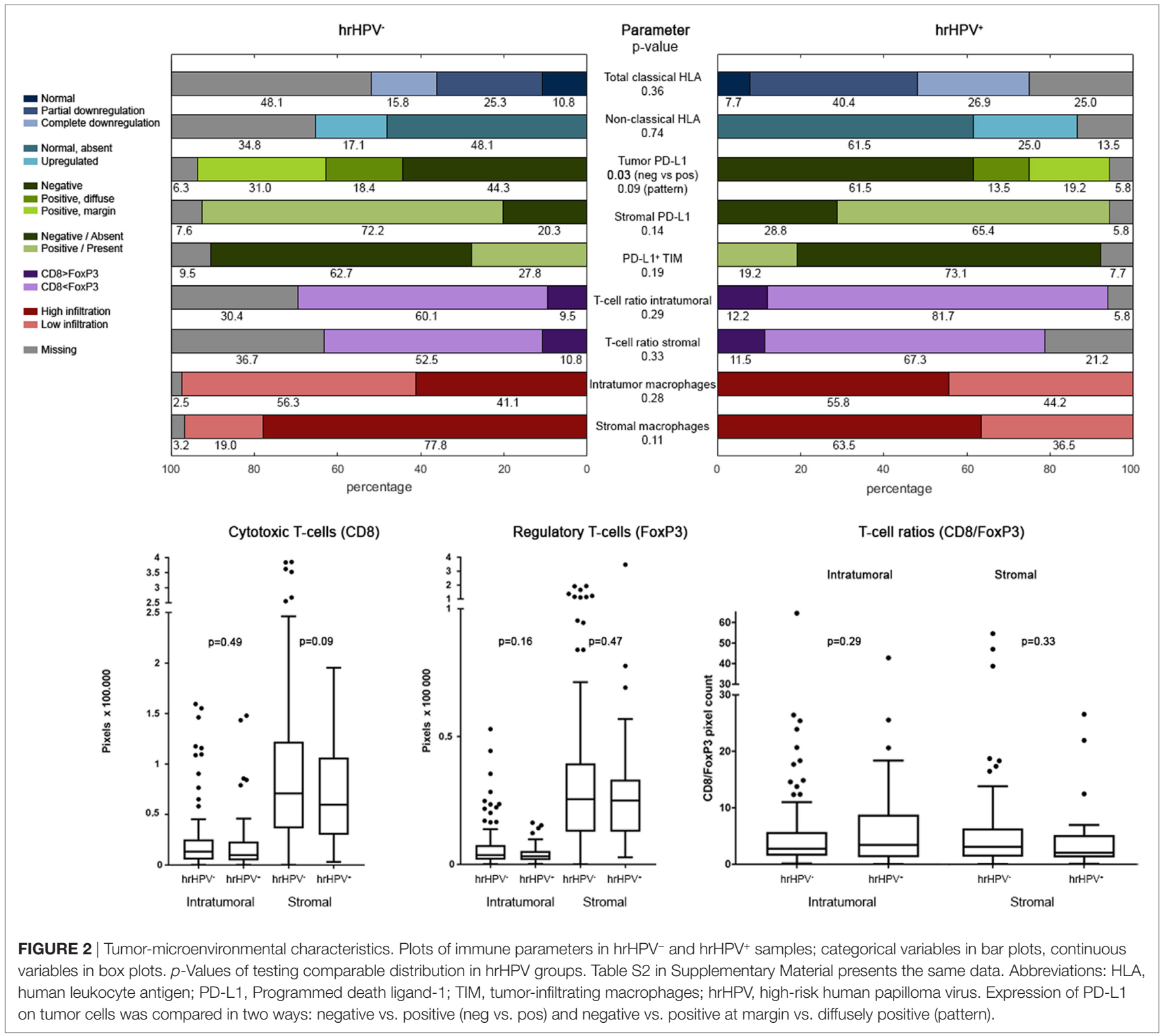



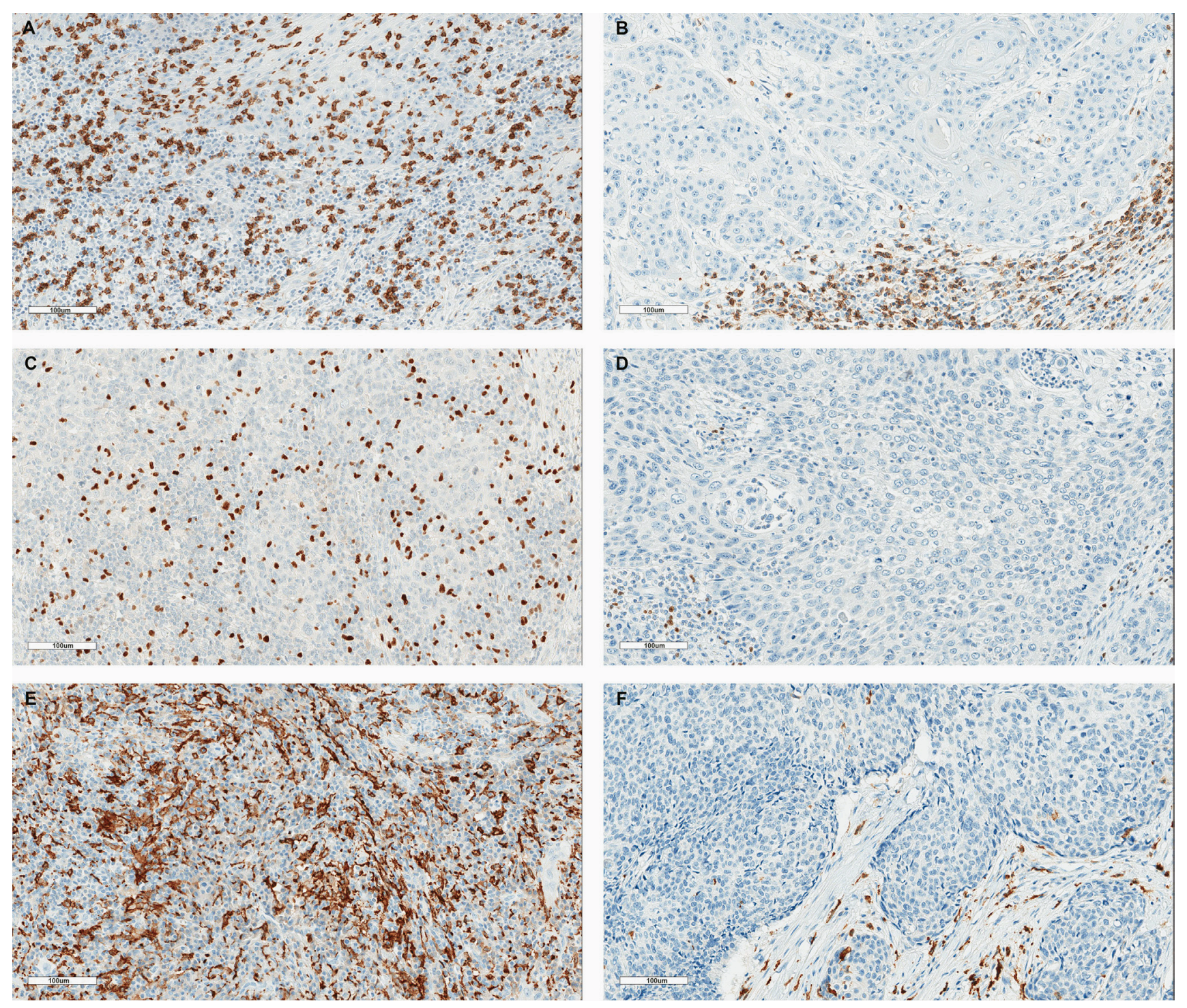

FIGURE 3 | Examples of representative stainings for high and low infiltration of CD8 ${ }^{+}$T cells (A,B), FoxP3 ${ }^{+}$regulatory T-cells (C,D), and CD163+ macrophages (E,F). Scale bars: $100 \mu \mathrm{m}$.

In addition, to determine the subtype of macrophages infiltrating penile tumors, a fluorescent double staining of CD163 and CD68 was performed (Figures $4 \mathbf{A}, \mathbf{B}$ ) and the majority of cells were found to be $\mathrm{CD} 68^{+} \mathrm{CD} 163^{+}$both intratumoral and in stromal areas, indicative of M2-polarization of virtually all macrophages in these tumors.

\section{Univariable Analyses}

\section{Associations Between TME Factors and LNM}

Results from the univariable analysis are presented in Table 2. With clinicopathological parameters and updated follow-up of patients, results resembled our previous reports $(7,9,11)$. Tumor PD-L1 expression was significantly associated with LNM; diffusely PD-L1-positive tumors had higher odds of LNM in comparison to tumors with marginal PD-L1 expression only [OR
4.16, $p<0.01]$ and to tumors with combined negative/margin PD-L1 expression (OR 3.28, $p<0.01$ ). Presence of PD-L1 ${ }^{+}$TIM was associated with higher chance of LNM but not on a level of conventional statistical significance (OR 1.91, $p>0.05$ ). The presence of high numbers of intratumoral $\mathrm{CD}_{163}{ }^{+} \mathrm{M} 2$ macrophages was significantly associated with higher LNM incidence (OR $2.45, p<0.01)$.

Aberrant classical HLA class I expression patterns (combined score of HLA-A, HLA-B/C, and $\beta 2 \mathrm{~m}$ ) did not show significant associations with LNM. Interestingly, upregulation of nonclassical HLA class I molecules (combined score of HLA-E and HLA-G) was associated with a higher odds of LNM compared with normal expression (OR 2.28, $p=0.02)$.

The only T-cell infiltration parameter showing significant association with $\mathrm{LNM}$, was increased $\mathrm{CD}^{+} \mathrm{T}$-cell infiltration 

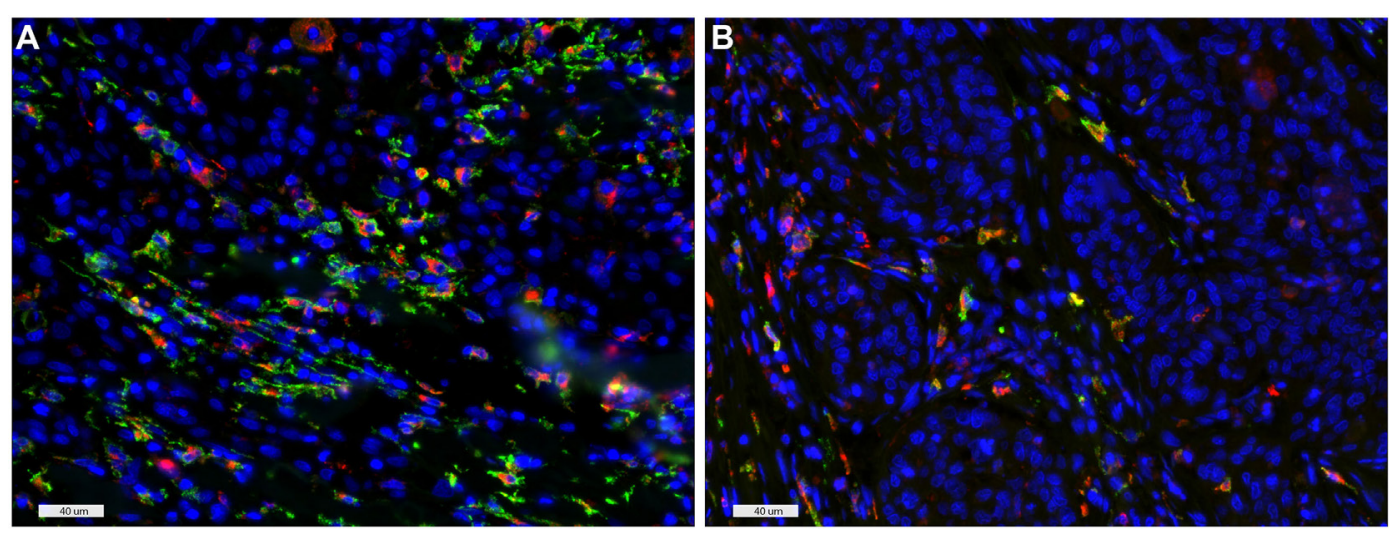

FIGURE 4 | CD163 and CD68 double staining of an hrHPV- (A) and hrHPV+ (B) case, indicative of M2 macrophage polarization. Colors: green, CD163; red, CD68; and blue, DAPI. Scale bars: $40 \mu \mathrm{m}$.

TABLE 2 | Univariable analysis.

\begin{tabular}{|c|c|c|c|c|c|}
\hline Variable & Contrast & \multicolumn{2}{|c|}{ Lymph node metastasis (LNM) } & \multicolumn{2}{|c|}{ Disease-specific survival (DSS) } \\
\hline \multicolumn{6}{|c|}{ Tumor-microenvironmental parameters } \\
\hline \multirow[t]{3}{*}{ PD-L1 pattern } & Negative vs. margin & $1.44[0.68-3.03]$ & 0.34 & $1.28[0.44-3.68]$ & 0.65 \\
\hline & Diffuse vs. margin & $4.16[1.71-10.17]$ & $<0.01$ & $4.35[1.53-12.34]$ & $<0.01$ \\
\hline & Diffuse vs. negative/margin & $3.28[1.58-6.84]$ & $<0.01$ & $3.70[1.75-7.82]$ & $<0.01$ \\
\hline \multirow[t]{2}{*}{ Classical HLA class I } & Complete vs. partial downregulation & $1.26[0.45-3.58]$ & 0.18 & $0.12[0.02-0.96]$ & $<0.05$ \\
\hline & Normal expression vs. partial downregulation & $0.69[0.22-2.19]$ & 0.66 & $0.45[0.10-2.00]$ & 0.29 \\
\hline Non-classical HLA class I & Upregulated vs. normal & $2.28[1.08-4.81]$ & 0.02 & $0.53[0.15-1.84]$ & 0.32 \\
\hline CD8 intratumoral & Per 100,000 pixels & $1.32[0.50-3.50]$ & 0.58 & $0.83[0.21-3.31]$ & 0.79 \\
\hline CD8 stromal & Per 100,000 pixels & $0.60[0.37-0.98]$ & 0.04 & $0.84[0.49-1.44]$ & 0.52 \\
\hline FoxP3 intratumoral & Per 100,000 pixels & $24.74[0.40-1,532.10]$ & 0.13 & $36.39[0.92-1,433.75]$ & 0.06 \\
\hline \multicolumn{6}{|c|}{ Clinicopathological parameters } \\
\hline Age & Per year & $1.00[0.98-1.02]$ & 0.95 & $1.01[0.98-1.04]$ & 0.40 \\
\hline Tumor size & Per cm & $1.11[0.97-1.26]$ & 0.13 & $1.21[1.07-1.37]$ & \\
\hline \multirow[t]{2}{*}{ pT stage } & pT2 vs. pT1a/b & $2.33[1.10-4.91]$ & 0.03 & $1.32[0.48-3.67]$ & 0.59 \\
\hline & pT3-4 vs. pT1a/b & $6.57[2.25-19.17]$ & $<0.01$ & $7.19[2.46-21.07]$ & $<0.01$ \\
\hline \multirow[t]{2}{*}{ Grade of differentiation } & Intermediate vs. good differentiation & $8.01[3.16-20.27]$ & $<0.01$ & $2.11[0.74-5.98]$ & 0.16 \\
\hline & Poor vs. good differentiation & $21.14[7.32-61.11]$ & $<0.01$ & $5.99[2.11-17.01]$ & $<0.01$ \\
\hline LVI & Present vs. absent & $4.65[2.11-10.23]$ & $<0.01$ & $3.21[1.45-7.10]$ & $<0.01$ \\
\hline Exophytic growth & Present vs. absent & $0.62[0.32-1.18]$ & 0.14 & $0.65[0.28-1.53]$ & 0.33 \\
\hline Lymph node status & $\mathrm{pN}+$ vs. pNO & - & - & $38.51[9.15-162.16]$ & $<0.01$ \\
\hline Extranodal growtha & Present vs. absent & - & - & $2.11[0.93-4.78]$ & 0.08 \\
\hline
\end{tabular}

OR, odds ratio; HR, hazard ratio; LVI, lymphovascular invasion; HPV, human papilloma virus; HLA, human leukocyte antigen; PD-L1, programmed death ligand-1; TIM, tumorinfiltrating macrophages.

aExluding cases with no LNM.

Bold numbers are statistically significant.

rate in tumor-associated stroma (OR 0.60, $p=0.04$ ) albeit with a confidence interval (95\% CI) almost including 1: 0.37-0.98.

\section{Associations Between TME Factors and DSS}

High-risk human papilloma virus negativity was associated with worse survival (HR 4.82, $p=0.03$ ), and complete downregulation of classical HLA class I with better survival than partial downregulation (HR $0.12, p<0.05$, note questionable $95 \% \mathrm{CI}$ of 0.02-0.96) (Table 2). A diffuse PD-L1 tumor expression pattern was associated with higher risk of disease-specific death than marginal PD-L1 expression ( $\mathrm{HR} 4.35, p<0.01$ ), and negative/ margin PD-L1 expression (HR 3.70, $p<0.01$ ). 
Although we saw some evidence of associations of DSS with intratumoral Tregs (HR 36.39, $p=0.06$ ) and high intratumoral $\mathrm{CD}_{163}{ }^{+} \mathrm{M} 2$-macrophage infiltration (HR 2.10, $p \geq 0.05$ ), these associations were not significant.

\section{Multivariable Analysis}

Classical and non-classical HLA were non-significant in the multivariable models (data not shown). These variables limited the number of included cases in the multivariable models because of a relatively high number of missing values, and therefore they were excluded from the final models to increase the sample size.

In the multivariable analysis (Table 3), diffuse PD-L1 expression was the only immunological factor that remained significantly associated with LNM, although the lower limit of the confidence interval was just above 1 (OR 2.81, 95\% CI [1.01-7.81], $p<0.05$ ). hrHPV negativity and diffuse PD-L1 expression were immune factors predicting poor survival in the multivariable model (OR 9.73, $p<0.01$, and OR 2.78, $p=0.03$, respectively).

\section{Subgroup Analyses}

$\mathrm{hrHPV}^{+}$and $\mathrm{hrHPV}^{-}$penile cancer can be seen as two different tumor entities, and patients with $\mathrm{hrHPV}^{-}$tumors have a higher risk of dying from this disease (7). Also, various histological subtypes of SCC have a distinct better or poorer prognosis (38). Therefore, analyses were repeated in the $\mathrm{hrHPV}^{-}$subgroup, and the subgroup with usual histological subtype SCC (Tables 4 and 5).

TABLE 3 | Multivariable backward regression analysis.

\begin{tabular}{llcc}
\multicolumn{2}{l}{ Lymph node metastasis } & & \\
\hline Variable & Contrast & OR [Cl] & $\boldsymbol{p}$-Value \\
\hline Tumor PD-L1 & Diffuse vs. negative/margin & $2.81[1.01-7.81]$ & $\mathbf{0 . 0 5}$ \\
PD-L1+ TIM & Present vs. absent & - & - \\
CD8 stromal & Per 100,000 pixels increase & $0.54[0.27-1.05]$ & 0.07 \\
CD163 & High vs. low infiltration & - & - \\
intratumoral & & $3.18[1.08-9.35]$ & $\mathbf{0 . 0 4}$ \\
LVI & Present vs. absent & $6.76[2.11-21.63]$ & $<\mathbf{0 . 0 1}$ \\
Grade of & Intermediate vs. good & & \\
differentiation & differentiation & $12.07[3.19-45.70]$ & $<\mathbf{0 . 0 1}$ \\
& Poor vs. good differentiation & - & - \\
pT stage & pT2 vs. pT1a/b & - & - \\
\hline
\end{tabular}

Disease-specific survival

\begin{tabular}{llcr}
\hline Variable & Contrast & HR [Cl] & p-Value \\
\hline High-risk HPV & Absent vs. present & $9.73[2.12-44.72]$ & $<\mathbf{0 . 0 1}$ \\
Tumor PD-L1 & Diffuse vs. negative/margin & $2.78[1.10-6.98]$ & $\mathbf{0 . 0 3}$ \\
$\begin{array}{l}\text { FoxP3 } \\
\text { intratumoral }\end{array}$ & Per 1,000 pixels increase & - & - \\
$\begin{array}{l}\text { CD163 } \\
\text { intratumoral }\end{array}$ & High vs. low infiltration & - & - \\
Tumor size & Per cm & & \\
$\begin{array}{l}\text { Lymph node } \\
\text { status }\end{array}$ & pN+ vs. pN0 & $1.31[1.11-1.53]$ & $<\mathbf{0 . 0 1}$ \\
Grade of & Intermediate vs. good & 63.21 & $<\mathbf{0 . 0 1}$ \\
differentiation & differentiation & $0.30[0.09-1.06]$ & 0.06 \\
& Poor vs. good differentiation & $0.87[0.26-2.90]$ & 0.81
\end{tabular}

OR, odds ratio; $C l, 95 \%$ confidence interval for OR/HR; PD-L1, programmed death ligand-1; TIM, tumor-infiltrating macrophages LVI, Iymphovascular invasion; HR, hazard ratio; HPV, human papilloma virus; -, excluded during regression analysis.

Bold numbers are statistically significant.

\section{hrHPV-Negative Subgroup}

In univariable analysis of the $\mathrm{hrHPV}^{-}$subgroup $(n=158)$, three factors were significantly associated with LNM: a diffuse PD-L1 expression pattern (OR 4.18, $p<0.01)$, high intratumoral infiltration rates of $\mathrm{CD} 63^{+}$macrophages (OR 2.17, $p=0.03$ ), andassociated with lower risk of LNM-high stromal $\mathrm{CD}^{+} \mathrm{T}$-cell infiltration (OR $0.45, p=0.02$ ). Diffuse PD-L1 expression pattern and high intratumoral $\mathrm{CD} 163^{+}$macrophage infiltration were also significantly associated with worse DSS (HR 6.19, $p<0.01$ and HR 2.17, $p<0.05$ ).

Multivariable regression analysis of the $\mathrm{hrHPV}^{-}$subgroup, showed grade of differentiation as the only significant factor associated with LNM (OR 15.30 and 19.34 for grades 2 and 3 compared with grade 1 , both $p<0.01$ ). High stromal CD $8^{+} \mathrm{T}$ cell infiltration showed some evidence of negative association with LNM but was not statistically significant (OR 0.44, $p=0.06$ ). PD-L1 expression pattern was eliminated during backward selection.

For DSS in the hrHPV ${ }^{-}$subgroup, LNM (HR 82.22, $\left.p<0.01\right)$ and diffuse PD-L1 expression pattern (OR 5.03, $p<0.01$ ) remained the most important factors in the multivariable model. High FoxP3 ${ }^{+}$Treg infiltration rates were associated with worse DSS but did not meet statistical significance (OR 183.89, $p \geq 0.05)$.

\section{Usual Histological Subtype SCC}

Univariable analysis in the usual histological subtypes $(n=180)$, showed-similar to the $\mathrm{hrHPV}^{-}$subgroup-significant associations with LNM for PD-L1 expression pattern (OR 3.17, $p=0.02$ ) and high intratumoral $\mathrm{CD} 163^{+}$macrophage infiltration rates $(\mathrm{OR}$ 2.36, $p<0.01$ ), and a negative association with LNM for high stromal $\mathrm{CD}^{+} \mathrm{T}$-cell infiltration (OR $0.45, p=0.03$ ) (Tables 4 and 5). Unlike the $\mathrm{hrHPV}^{-}$subgroup, LNM were also associated with PD-L1-expressing TIM (OR 2.10, $p=0.04$ ). Poor DSS was associated with presence of diffuse PD-L1 expression pattern (HR 4.22, $p=0.02$ ) and high intratumoral $\mathrm{CD} 163^{+}$macrophage infiltration (HR 2.28, $p<0.05)$.

After multivariable regression, the final model for LNM included grade of differentiation (similar values as $\mathrm{hrHPV}^{-}$), high stromal CD8 (OR 0.38, $p=0.01$ ) and pT stage (OR 10.14, $p=0.02$ for T3/T4 vs. T1). Like in the $\mathrm{hrHPV}^{-}$subgroup, PD-L1 was eliminated during backward selection. For DSS, having lymph node metastases was the most important predictor of survival (HR 124.33, $p<0.01)$. The multivariable model also included hrHPV negativity (HR 6.82, $p<0.01$ ) and other clinical predictors.

\section{DISCUSSION}

This is the largest study that reports on associations of multiple TME factors with patient outcomes adjusted for clinical predictors in penile cancer.

In the total cohort, diffuse PD-L1 tumor-cell expression, $\mathrm{CD}_{163}{ }^{+}$macrophage infiltration, non-classical HLA class I upregulation and low stromal $\mathrm{CD}^{+} \mathrm{T}$-cell infiltration, were all associated with LNM. In the multivariable model, only PD-L1 expression remained a significant predictor for LNM (OR 2.81, $p=0.05)$. hrHPV negativity and diffuse PD-L1 tumor-cell 
TABLE 4 | Univariable subgroup analysis.

Univariable subgroup analysis

\begin{tabular}{|c|c|c|c|c|c|}
\hline \multirow{2}{*}{$\begin{array}{l}\text { hrHPV- subgroup }(N=158) \\
\text { Variable }\end{array}$} & \multirow[b]{2}{*}{ Contrast } & \multicolumn{2}{|c|}{ Lymph node metastasis (LNM) } & \multicolumn{2}{|c|}{ Disease-specific survival (DSS) } \\
\hline & & OR [CI] & $p$-Value & $\mathrm{HR}[\mathrm{Cl}]$ & $p$-Value \\
\hline \multirow[t]{3}{*}{ PD-L1 pattern } & Negative vs. margin & $1.67[0.71-3.96]$ & 0.24 & $1.86[0.58-5.93]$ & 0.30 \\
\hline & Diffuse vs. margin & $4.18[1.53-11.43]$ & $<0.01$ & $6.19[2.00-19.22]$ & $<0.01$ \\
\hline & Diffuse vs. negative/margin & $3.04[1.32-7.01]$ & $<0.01$ & $4.15[1.92-8.98]$ & $<0.01$ \\
\hline PD-L1 stroma & Positive vs. negative & $0.98[0.42-2.27]$ & 0.95 & $1.42[0.49-4.15]$ & 0.52 \\
\hline PD-L1 TIM & Present vs. absent & $1.52[0.72-3.25]$ & 0.28 & $1.46[0.64-3.33]$ & 0.37 \\
\hline \multirow{2}{*}{ Total classical HLA class I } & Partial downregulation vs. normal expression & $2.17[0.60-7.85]$ & 0.24 & $0.13[0.02-1.01]$ & 0.05 \\
\hline & Complete downregulations vs. normal expression & $1.26[0.31-5.23]$ & 0.75 & $0.37[0.08-1.66]$ & 0.19 \\
\hline Total non-classical HLA class I & Upregulated vs. normal & $1.84[0.75-4.55]$ & 0.15 & $0.59[0.17-2.07]$ & 0.41 \\
\hline CD8 intratumoral & Per 100,000 pixels & $0.83[0.24-2.85]$ & 0.77 & $0.80[0.18-3.62]$ & 0.77 \\
\hline CD8 stromal & Per 100,000 pixels & $0.45[0.23-0.88]$ & 0.02 & $0.80[0.45-1.43]$ & 0.46 \\
\hline FoxP3 intratumoral & Per 100,000 pixels & $18.21[0.25-1,345.66]$ & 0.19 & $22.69[0.58-891.96]$ & 0.10 \\
\hline FoxP3 stromal & Per 100,000 pixels & $0.71[0.22-2.27]$ & 0.56 & $0.52[0.12-2.35]$ & 0.40 \\
\hline T-cell ratio intratumoral & Continuous & $1.00[0.95-1.05]$ & 0.96 & $0.93[0.81-1.05]$ & 0.24 \\
\hline T-cell ratio stromal & Continuous & $0.95[0.86-1.04]$ & 0.24 & 0.99 [0.93-1.06] & 0.74 \\
\hline CD163 intratumoral & High vs. low infiltration & 2.17 [1.10-4.30] & 0.03 & 2.17 [1.10-4.30] & 0.05 \\
\hline CD163 stromal & High vs. low infiltration & $1.43[0.59-3.48]$ & 0.44 & $1.23[0.59-3.48]$ & 0.44 \\
\hline \multicolumn{2}{|l|}{ Usual SCC subgroup $(N=180)$} & \multicolumn{2}{|l|}{ LNM } & \multicolumn{2}{|l|}{ DSS } \\
\hline Variable & Contrast & OR [Cl] & $p$-Value & $\mathrm{HR}[\mathrm{Cl}]$ & $p$-Value \\
\hline High-risk HPV & Negative vs. positive & 1.17 [0.56-2.45] & 0.68 & $4.04[0.96-17.10]$ & 0.06 \\
\hline \multirow[t]{3}{*}{ PD-L1 pattern } & Negative vs. margin & 1.37 [0.62-3.04] & 0.44 & $1.65[0.52-5.17]$ & 0.39 \\
\hline & Diffuse vs. margin & 3.17 [1.23-8.18] & 0.02 & $4.22[1.32-13.45]$ & 0.02 \\
\hline & Diffuse vs. negative/margin & 2.58 [1.17-5.67] & 0.02 & 3.01 [1.35-6.69] & $<0.01$ \\
\hline PD-L1 stroma & Positive vs. negative & 0.79 [0.37-1.68] & 0.54 & $1.12[0.42-3.00]$ & 0.82 \\
\hline PD-L1 TIM & Present vs. absent & $2.10[1.05-4.20]$ & 0.04 & $1.70[0.75-3.82]$ & 0.20 \\
\hline \multirow[t]{2}{*}{ Total classical HLA class I } & Partial downregulation vs. normal expression & $1.20[0.41-3.52]$ & 0.74 & $0.00[0.00-0.00]$ & 0.96 \\
\hline & Complete downregulations vs. normal expression & $0.48[0.13-1.75]$ & 0.27 & $0.46[0.10-2.12]$ & 0.32 \\
\hline Total non-classical HLA class I & Upregulated vs. normal & $2.14[0.97-4.75]$ & 0.06 & 0.59 [0.17-2.08] & 0.41 \\
\hline CD8 intratumoral & Per 100,000 pixels & $1.21[0.38-3.80]$ & 0.75 & $0.79[0.17-3.60]$ & 0.76 \\
\hline CD8 stromal & Per 100,000 pixels & $0.55[0.32-0.93]$ & 0.03 & $0.81[0.47-1.40]$ & 0.45 \\
\hline FoxP3 intratumoral & Per 100,000 pixels & $40.50[0.53-3,085.53]$ & 0.09 & $19.38[0.34-1,114.01]$ & 0.15 \\
\hline FoxP3 stromal & Per 100,000 pixels & $0.0 .59[0.20-1.74]$ & 0.34 & $0.69[0.18-2.74]$ & 0.60 \\
\hline T-cell ratio intratumoral & Continuous & $0.98[0.92-1.04]$ & 0.51 & 0.97 [0.88-1.06] & 0.45 \\
\hline T-cell ratio stromal & Continuous & $0.96[0.90-1.03]$ & 0.24 & 0.99 [0.93-1.06] & 0.92 \\
\hline CD163 intratumoral & High vs. low infiltration & $2.36[1.25-4.48]$ & $<0.01$ & $2.28[1.02-5.11]$ & 0.05 \\
\hline CD163 stromal & High vs. low infiltration & 2.03 [0.89-4.59] & 0.09 & 1.60 [0.55-4.65] & 0.39 \\
\hline
\end{tabular}

OR, odds ratio; HR, hazard ratio; CI, 95\% confidence interval for OR/HR; LVI, lymphovascular invasion; hrHPV, high-risk human papilloma virus; HLA, human leukocyte antigen; PD-L1, Programmed death ligand-1; TIM, tumor-infiltrating macrophages; SCC, squamous cell carcinoma; -, excluded from the multivariable model during regression analysis; NA, not applicable. Bold numbers are statistically significant.

expression were significantly associated with poor DSS and remained so upon correction for clinical parameters (HR 9.73, $p<0.01$ and HR 2.81, $p=0.03$ ).

The strong prognostic value for hrHPV reflects two tumor entities, similar to head-and-neck SCC and vulvar SCC (39-41). One is hrHPV-mediated, more immunogenic, and associated with better prognosis $(41,42)$. The other is HPV-independent, induced by chronic irritation, inflammation and genetic alterations $(39,40,43)$. Interestingly, the only immune factor that differed from $\mathrm{HPV}^{+}$to $\mathrm{HPV}^{-}$tumors was $\mathrm{PD}-\mathrm{L} 1$ expression, with higher PD-L1 expression rates in the latter $(p=0.03)$. In the $\mathrm{HPV}^{-}$ cohort $(n=158)$, LNM were associated with diffuse PD-L1 tumor-cell expression, high intratumoral $\mathrm{CD} 63^{+}$macrophage infiltration and low number of stromal $\mathrm{CD}^{+} \mathrm{T}$-cells, while only the first two parameters were associated with DSS. In the $\mathrm{HPV}^{-}$subgroup multivariable regression model, diffuse PD-L1 expression remained significantly associated with poor DSS (HR
5.03, $p<0.01)$. Similar results were obtained when the cohort analysis was restricted to the usual histological subtype SCC.

The contrasting associations of diffuse PD-L1 expression with poor outcomes and PD-L1 expression at the tumor-stroma margin with more favorable outcomes can be explained by two different pathways of PD-L1 expression, identified in melanoma and gynecological SCC (44-47). The first has a genetic background (deregulated signaling pathways, transcription factors and numerical aberrations) resulting in CD274 overexpression, and concomitant diffuse PD-L1 expression $(15,44,46)$. The other is a reactive, interferon-gamma (IFN $\gamma$ ) induced expression at the tumor-stroma margin, explaining its favorable role $(45,47)$. We hypothesized that the better survival of cases with tumor-margin PD-L1 expression is explained by accumulation of activated T-cells and IFN $\gamma$ release in the adjacent stroma (11). But among the PD-L1-positive tumors, stromal CD8 ${ }^{+} \mathrm{T}$-cell infiltration was not associated with a marginal expression pattern (data not shown, 
TABLE 5 | Multivariable subgroup analysis.

Multivariable subgroup analysis

\begin{tabular}{|c|c|c|c|c|c|}
\hline \multirow{2}{*}{$\begin{array}{l}\text { Lymph node metastasis (LNM) } \\
\text { Variables included in model }\end{array}$} & \multirow[b]{2}{*}{ Contrast } & \multicolumn{2}{|c|}{ hrHPV- } & \multicolumn{2}{|l|}{ Usual SCC } \\
\hline & & OR [Cl] & $p$-Value & OR $[\mathrm{Cl}]$ & $p$-Value \\
\hline Tumor PD-L1 & Diffuse vs. negative/margin & - & - & - & - \\
\hline PD-L1+ TIM & Present vs. absent & - & - & - & - \\
\hline CD8 stromal & Per 100,000 pixels increase & $0.44[0.18-1.05]$ & 0.06 & $0.38[0.18-0.81]$ & 0.01 \\
\hline CD163 intratumoral & High vs. low infiltration & - & - & - & - \\
\hline LVI & Present vs. absent & 3.91 [0.93-18.37] & 0.08 & - & - \\
\hline \multirow[t]{2}{*}{ Grade of differentiation } & Intermediate vs. good differentiation & $15.30[3.86-60.66]$ & $<0.01$ & 6.09 [1.82-20.44] & $<0.01$ \\
\hline & Poor vs. good differentiation & $19.34[3.92-95.53]$ & $<0.01$ & $19.11[4.34-84.11]$ & $<0.01$ \\
\hline \multirow[t]{2}{*}{ pT stage } & pT2 vs. pT1 & - & - & $1.43[0.45-4.48]$ & 0.55 \\
\hline & pT3-4 vs. pT1 & - & - & $10.14[1.39-73.84]$ & 0.02 \\
\hline Disease-specific survival & & \multicolumn{2}{|l|}{ hrHPV- } & \multicolumn{2}{|l|}{ Usual SCC } \\
\hline Variables included in model & Contrast & $\mathrm{HR}[\mathrm{Cl}]$ & $p$-Value & $\mathrm{HR}[\mathrm{Cl}]$ & $p$-Value \\
\hline High-risk HPV & Absent vs. present & NA & NA & $6.82[1.49-31.37]$ & 0.01 \\
\hline Tumor PD-L1 & Diffuse vs. negative/margin & $5.03[1.81-13.99]$ & $<0.01$ & $2.48[0.91-6.80]$ & 0.08 \\
\hline FoxP3 intratumoral & Per 1,000 pixels increase & 183.89 [0.96-35,153.22] & $>0.05$ & - & - \\
\hline CD163 intratumoral & High vs. low infiltration & - & - & - & - \\
\hline Tumor size & Per $\mathrm{cm}$ & $1.47[1.23-1.76]$ & $<0.01$ & $1.32[1.12-1.55]$ & $<0.01$ \\
\hline Lymph node status & $\mathrm{pN}+$ vs. pNO & 82.22 [14.99-450.90] & $<0.01$ & $124.33[14.51-1,065.27]$ & $<0.01$ \\
\hline \multirow[t]{2}{*}{ Grade of differentiation } & Intermediate vs. good differentiation & $0.25[0.07-0.91]$ & 0.04 & $0.25[0.07-0.92]$ & 0.04 \\
\hline & Poor vs. good differentiation & $0.84[0.25-2.86]$ & 0.78 & $0.71[0.22-2.34]$ & 0.57 \\
\hline
\end{tabular}

hrHPV, high-risk human papilloma virus; OR, odds ratio; CI, 95\% confidence interval; PD-L1, programmed death ligand-1; TIM, tumor-infiltrating macrophages; LVI, Iymphovascular invasion; HR, hazard ratio; SCC, squamous cell carcinoma; -, excluded from the multivariable model during regression analysis.

Bold numbers are statistically significant.

Spearman, $p=0.819)$. The higher number of diffusely PD-L1 positive tumors in the $\mathrm{hrHPV}^{-}$group of our cohort, however, fits the hypothesis of a more mutated tumor type with higher T-cell inhibition properties, partially explaining poorer survival. Deng et al. studied PD-L1 expression and tumor-infiltrating lymphocytes in penile cancer and also did functional analyses on cell lines (14). They found PD-L1 expression positively correlated with IFN $\gamma$ and $\mathrm{CD}^{+}$gene expression, suggesting that indeed PD-L1 expression was induced by activated T-cells $(14,45)$. The proportion of $\mathrm{hrHPV}^{+}$tumors in their study is presumably low (prevalence in Asia around 13\%) (14). Recent studies in oropharyngeal SCC reported on a prognostic role for $\mathrm{CD}^{+} \mathrm{T}$-cell infiltration rates and not for PD-L1 expression $(17,48)$. Like us, Oguejiofor et al. found higher PD-L1 expression in $\mathrm{HPV}^{-}$tumors (17). However, they also investigated $\mathrm{CD} 8^{+} \mathrm{T}$-cells expressing the $\mathrm{PD}-\mathrm{L} 1$ receptor PD-1 and found higher proportions of CD8 $8^{+} \mathrm{PD}-1^{+} \mathrm{T}$-cells in stroma than in tumor. Considering higher PD-L1 expression in $\mathrm{hrHPV}^{-}$tumors, this suggests pronounced T-cell inhibition in this unfavorable group. In HNSCC, CD8 ${ }^{+} \mathrm{T}$-cells were more frequent in $\mathrm{HPV}^{+}$tumors, and also more capable of producing IFN $\gamma$ (20). Another study found that not only composition but also location of suppressive factors matter; PD-L1 ${ }^{+}$or FoxP3 ${ }^{+}$ cells close to $\mathrm{CD}^{+}$T-cells (within $30 \mu \mathrm{m}$ ) are associated with worse overall survival (48). We did not assess PD-1 expression, IFN $\gamma$-producing capacity or proximity of suppressive factors in our cohort, but these factors may influence the different outcomes of patients with $\mathrm{hrHPV}^{+}$and hrHPV ${ }^{-}$tumors.

Cocks et al. found a decreased $\mathrm{CD} 8^{+} \mathrm{T}$ cell/FoxP3 ${ }^{+}$Treg-ratio associated with tumor progression during follow-up in penile cancer patients, but no associations with overall survival or DSS
(12). We also found no associations with this ratio and did not use progression during follow-up as outcome. These discrepancies can be partially explained by technical differences (they performed hot-spot analysis in TMAs). But also by factors that are not included in our analysis, such as other checkpoint molecules (e.g., CTLA-4) and PD-1 expression on T-cells.

Based on our results, can we inverse tumor escape in penile carcinomas, and how?

First, with PD-L1 as one of the most important predictors of prognosis in penile SCC, trials with PD-(L)1-checkpointinhibitors are warranted. Systemic treatment with these agents has been FDA-approved for various cancers, including SCCs (49). In the Netherlands Cancer Institute, we are currently planning a clinical trial with such agents in advanced penile cancer.

Second, the favorable high stromal $\mathrm{CD}^{+} \mathrm{T}$ cell and low intratumoral $\mathrm{CD} 63^{+}$macrophage infiltration should be notified as important mechanisms. M2-polarized macrophages play a crucial role in T-cell response suppression, angiogenesis and treatment evasion, but can be reprogrammed toward activated $\mathrm{M} 1$ macrophages by $\mathrm{CD} 4^{+}$helper T-cells $(30,31,50)$. In the future, combinational immunotherapies should be applied to counter the adverse effects of the complex microenvironment in these tumors (51).

Limitations of the study include the relatively few cases with LNM and disease associated deaths in this cohort, and the substantial missing values in HLA expression due to insufficient tissue material for TMA sampling (9). Both limited the statistical analysis. Second, we did not determine PD-1 expression, distance from $\mathrm{CD}^{+} \mathrm{T}$-cells to $\mathrm{PD}-\mathrm{L} 1$ expressing tumor cells and tumorassociated macrophages, or functionality (48). Furthermore, our results ideally are externally validated. 
Nevertheless, our results favor the rationale for immunotherapy for this mutilating disease. Any effectiveness of immunotherapy on primary tumor or LNM has to be revealed by future clinical studies, stratifying patients based on TME parameters, eventually leading to personalized immunotherapy. We are currently focusing on comparing the TME of primary tumors to metastatic lymph nodes.

In conclusion, in this study, we showed that the penile cancer microenvironment is highly complex and contains various targets for immunotherapy. These results can aid risk-stratification and importantly, the here described TME factors should be evaluated in future immunotherapy clinical studies to ultimately lead to patient tailored treatment.

\section{DATA AVAILABILITY STATEMENT}

Datasets are available on request.

\section{AUTHOR CONTRIBUTIONS}

This study was designed by $\mathrm{SH}$ and EJ. Scoring of samples was done by SO, RD, PJ, AH, JJ, JS, and EJ. Clinicopathological data

\section{REFERENCES}

1. Hansen BT, Orumaa M, Lie AK, Brennhovd B, Nygard M. Trends in incidence, mortality and survival of penile squamous cell carcinoma in Norway 1956-2015. Int J Cancer (2017) 142(8):1586-93. doi:10.1002/ijc.31194

2. Barnholtz-Sloan JS, Maldonado JL, Pow-sang J, Giuliano AR. Incidence trends in primary malignant penile cancer. Urol Oncol (2007) 25:361-7. doi:10.1016/j. urolonc.2006.08.029

3. Kirrander P, Sherif A, Friedrich B, Lambe M, Håkansson U; Steering Committee of the Swedish National Penile Cancer Register. Swedish National Penile Cancer Register: incidence, tumour characteristics, management and survival. BJU Int (2016) 117:287-92. doi:10.1111/bju.12993

4. Hakenberg OW, Compérat E, Minhas S, Necchi A, Protzel C, Watkin NA. EAU Guidelines on Penile Cancer. (2018). Available from: http://uroweb.org/ guideline/penile-cancer/ (Accessed: March 25, 2018).

5. Nyitray AG, Iannacone MR. The epidemiology of human papillomaviruses. Curr Probl Dermatol (2014) 45:75-91. doi:10.1159/000358370

6. Chaux A, Cubilla AL, Haffner MC, Lecksell KL, Sharma R, Burnett AL, et al. Combining routine morphology, p16(INK4a) immunohistochemistry, and in situ hybridization for the detection of human papillomavirus infection in penile carcinomas: a tissue microarray study using classifier performance analyses. Urol Oncol (2014) 32:171-7. doi:10.1016/j.urolonc.2012.04.017

7. Djajadiningrat RS, Jordanova ES, Kroon BK, van Werkhoven E, de Jong J, Pronk DTM, et al. Human papillomavirus prevalence in invasive penile cancer and association with clinical outcome. J Urol (2015) 193:526-31. doi:10.1016/j. juro.2014.08.087

8. Lohneis P, Boral S, Kaufmann AM, Lehmann A, Schewe C, Dietel M, et al. Human papilloma virus status of penile squamous cell carcinoma is associated with differences in tumour-infiltrating T lymphocytes. Virchows Arch (2015) 466:323-31. doi:10.1007/s00428-014-1713-4

9. Djajadiningrat RS, Horenblas S, Heideman DAM, Sanders J, de Jong J, Jordanova ES. Classic and nonclassic HLA class I expression in penile cancer and relation to HPV status and clinical outcome. J Urol (2015) 193:1245-51. doi:10.1016/j.juro.2014.11.057

10. Vassallo J, Rodrigues AFF, Campos AHJFM, Rocha RM, da Cunha IW, Zequi SC, et al. Pathologic and immunohistochemical characterization of tumoral inflammatory cell infiltrate in invasive penile squamous cell carcinomas: Fox-P3 expression is an independent predictor of recurrence. Tumour Biol (2015) 36:2509-16. doi:10.1007/s13277-014-2864-2

11. Ottenhof SR, Djajadiningrat RS, de Jong J, Thygesen $\mathrm{HH}$, Horenblas S, Jordanova ES. Expression of programmed death ligand 1 (PD-L1) in penile were collected by $\mathrm{SO}$ and $\mathrm{RD}$, parts of it were revised by JJ. $\mathrm{AH}$ performed CD163/CD86 double stainings. Statistical analysis was done by SO, HT, and KJ. The manuscript was drafted by SO, sections of it were written by $\mathrm{AH}$ and EJ. The manuscript was critically reviewed, read, and approved by all co-authors.

\section{ACKNOWLEDGMENTS}

We like to acknowledge the NKI-AVL Core Facility Molecular Pathology \& Biobanking (CFMPB) for supplying Netherlands Cancer Institute-Antoni van Leeuwenhoek biobank material, staining, and technical support. We like to thank René Musters for using the digital imaging fluorescence microscope and thank Judith Bosschieter for her efforts in scoring histological slides.

\section{SUPPLEMENTARY MATERIAL}

The Supplementary Material for this article can be found online at https://www.frontiersin.org/articles/10.3389/fimmu.2018.01253/ full\#supplementary-material.

cancer is of prognostic value and associated with HPV status. J Urol (2016) 197(3 Pt 1):690-7. doi:10.1016/j.juro.2016.09.088

12. Cocks M, Taheri D, Ball MW, Bezerra SM, Del Carmen Rodriguez M, Ricardo BFP, et al. Immune checkpoint status in penile squamous cell carcinoma: a North American cohort. Hum Pathol (2016) 59:55-61. doi:10.1016/j.humpath. 2016.09.003

13. Udager AM, Liu T-Y, Skala SL, Magers MJ, McDaniel AS, Spratt DE, et al. Frequent PD-L1 expression in primary and metastatic penile squamous cell carcinoma: potential opportunities for immunotherapeutic approaches. Ann Oncol (2016) 27:1706-12. doi:10.1093/annonc/mdw216

14. Deng C, Li Z, Guo S, Chen P, Chen X, Zhou Q, et al. Tumor PD-L1 expression is correlated with increased TILs and poor prognosis in penile squamous cell carcinoma. Oncoimmunology (2017) 6:e1269047. doi:10.1080/2162402X.2016. 1269047

15. Fridman WH, Zitvogel L, Sautes-Fridman C, Kroemer G. The immune contexture in cancer prognosis and treatment. Nat Rev Clin Oncol (2017) 14(12):717-34. doi:10.1038/nrclinonc.2017.101

16. Blank CU, Haanen JB, Ribas A, Schumacher TN. The cancer immunogram. Science (2016) 352:658-60. doi:10.1126/science.aaf2834

17. Oguejiofor K, Galletta-Williams H, Dovedi SJ, Roberts DL, Stern PL, West CML. Distinct patterns of infiltrating CD8+ T cells in HPV + and CD68 macrophages in HPV- oropharyngeal squamous cell carcinomas are associated with better clinical outcome but PD-L1 expression is not prognostic. Oncotarget (2017) 8:14416-27. doi:10.18632/oncotarget.14796

18. de Ruiter EJ, Ooft ML, Devriese LA, Willems SM. The prognostic role of tumor infiltrating T-lymphocytes in squamous cell carcinoma of the head and neck: a systematic review and meta-analysis. Oncoimmunology (2017) 6:e1356148. doi:10.1080/2162402X.2017.1356148

19. Zhang D, Tang W-J, Tang D, Zhou J, Chou L, Tao L, et al. The ratio of CD4/CD8 T-cells in human papillomavirus-positive laryngeal squamous cell carcinoma accounts for improved outcome. Acta Otolaryngol (2016) 136:826-33. doi:10. 3109/00016489.2016.1164341

20. Partlova S, Boucek J, Kloudova K, Lukesova E, Zabrodsky M, Grega M, et al. Distinct patterns of intratumoral immune cell infiltrates in patients with HPV-associated compared to non-virally induced head and neck squamous cell carcinoma. Oncoimmunology (2015) 4:e965570. doi:10.4161/21624011.2 014.965570

21. Gooden MJM, de Bock GH, Leffers N, Daemen T, Nijman HW. The prognostic influence of tumour-infiltrating lymphocytes in cancer: a systematic review with meta-analysis. Br J Cancer (2011) 105:93-103. doi:10.1038/bjc. 2011.189 
22. Adurthi S, Krishna S, Mukherjee G, Bafna UD, Devi U, Jayshree RS. Regulatory $\mathrm{T}$ cells in a spectrum of HPV-induced cervical lesions: cervicitis, cervical intraepithelial neoplasia and squamous cell carcinoma. Am J Reprod Immunol (2008) 60:55-65. doi:10.1111/j.1600-0897.2008.00590.x

23. De Meulenaere A, Vermassen T, Aspeslagh S, Vandecasteele K, Rottey S, Ferdinande L. TILs in head and neck cancer: ready for clinical implementation and why (not)? Head Neck Pathol (2017) 11:354-63. doi:10.1007/ s12105-016-0776-8

24. Zhao S, Jiang T, Zhang L, Yang H, Liu X, Jia Y, et al. Clinicopathological and prognostic significance of regulatory $\mathrm{T}$ cells in patients with non-small cell lung cancer: a systematic review with meta-analysis. Oncotarget (2016) 7:36065-73. doi:10.18632/oncotarget.9130

25. van Herk EH, Te Velde AA. Treg subsets in inflammatory bowel disease and colorectal carcinoma: characteristics, role, and therapeutic targets. J Gastroenterol Hepatol (2016) 31:1393-404. doi:10.1111/jgh.13342

26. Punt S, Dronkers EAC, Welters MJP, Goedemans R, Koljenovic S, Bloemena E, et al. A beneficial tumor microenvironment in oropharyngeal squamous cell carcinoma is characterized by a high T cell and low IL-17(+) cell frequency. Cancer Immunol Immunother (2016) 65:393-403. doi:10.1007/ s00262-016-1805-x

27. Chen P-L, Roh W, Reuben A, Cooper ZA, Spencer CN, Prieto PA, et al. Analysis of immune signatures in longitudinal tumor samples yields insight into biomarkers of response and mechanisms of resistance to immune checkpoint blockade. Cancer Discov (2016) 6:827-37. doi:10.1158/2159-8290. CD-15-1545

28. Hamid O, Schmidt H, Nissan A, Ridolfi L, Aamdal S, Hansson J, et al. A prospective phase II trial exploring the association between tumor microenvironment biomarkers and clinical activity of ipilimumab in advanced melanoma. J Transl Med (2011) 9:204. doi:10.1186/1479-5876-9-204

29. Becht E, Giraldo NA, Beuselinck B, Job S, Marisa L, Vano Y, et al. Prognostic and theranostic impact of molecular subtypes and immune classifications in renal cell cancer (RCC) and colorectal cancer (CRC). Oncoimmunology (2015) 4:e1049804. doi:10.1080/2162402X.2015.1049804

30. Qian B-Z, Pollard JW. Macrophage diversity enhances tumor progression and metastasis. Cell (2010) 141:39-51. doi:10.1016/j.cell.2010.03.014

31. De Palma M, Murdoch C, Venneri MA, Naldini L, Lewis CE. Tie2-expressing monocytes: regulation of tumor angiogenesis and therapeutic implications. Trends Immunol (2007) 28:519-24. doi:10.1016/j.it.2007.09.004

32. Alves AM, Diel LF, Lamers ML. Macrophages and prognosis of oral squamous cell carcinoma: a systematic review. J Oral Pathol Med (2017) 47(5):460-7. doi:10.1111/jop.12643

33. Chen X-J, Han L-F, Wu X-G, Wei W-F, Wu L-F, Yi H-Y, et al. Clinical significance of CD163+ and CD68+ tumor-associated macrophages in highrisk HPV-related cervical cancer. J Cancer (2017) 8:3868-75. doi:10.7150/ jca.21444

34. Leijte JAP, Kroon BK, Valdés Olmos RA, Nieweg OE, Horenblas S. Reliability and safety of current dynamic sentinel node biopsy for penile carcinoma. Eur Urol (2007) 52:170-7. doi:10.1016/j.eururo.2007.01.107

35. Ruiter DJ, Ferrier CM, van Muijen GN, Henzen-Logmans SC, Kennedy S, Kramer MD, et al. Quality control of immunohistochemical evaluation of tumour-associated plasminogen activators and related components. European BIOMED-1 concerted action on clinical relevance of proteases in tumour invasion and metastasis. Eur J Cancer (1998) 34:1334-40. doi:10.1016/ S0959-8049(98)00151-8

36. Keller MD, Neppl C, Irmak Y, Hall SR, Schmid RA, Langer R, et al. Adverse prognostic value of PD-L1 expression in primary resected pulmonary squamous cell carcinomas and paired mediastinal lymph node metastases. Mod Pathol (2018) 31:101-10. doi:10.1038/modpathol.2017.111

37. Ilie M, Hofman V, Dietel M, Soria J-C, Hofman P. Assessment of the PD-L1 status by immunohistochemistry: challenges and perspectives for therapeutic strategies in lung cancer patients. Virchows Arch (2016) 268:511-25. doi:10.1007/s00428-016-1910-4

38. Guimaraes GC, Cunha IW, Soares FA, Lopes A, Torres J, Chaux A, et al. Penile squamous cell carcinoma clinicopathological features, nodal metastasis and outcome in 333 cases. J Urol (2009) 182:528-34. doi:10.1016/j. juro.2009.04.028; discussion 534,

39. McAlpine JN, Leung SCY, Cheng A, Miller D, Talhouk A, Gilks CB, et al. Human papillomavirus (HPV)-independent vulvar squamous cell carcinoma has a worse prognosis than HPV-associated disease: a retrospective cohort study. Histopathology (2017) 71:238-46. doi:10.1111/his.13205

40. Krupar R, Robold K, Gaag D, Spanier G, Kreutz M, Renner K, et al. Immunologic and metabolic characteristics of HPV-negative and HPV-positive head and neck squamous cell carcinomas are strikingly different. Virchows Arch (2014) 465:299-312. doi:10.1007/s00428-014-1630-6

41. Mannweiler S, Sygulla S, Winter E, Regauer S. Two major pathways of penile carcinogenesis: HPV-induced penile cancers overexpress pl6ink4a, HPVnegative cancers associated with dermatoses express p53, but lack p16ink4a overexpression. JAm Acad Dermatol (2013) 69:73-81. doi:10.1016/j. jaad.2012.12.973

42. Mentrikoski MJ, Stelow EB, Culp S, Frierson HFJ, Cathro HP. Histologic and immunohistochemical assessment of penile carcinomas in a North American population. Am J Surg Pathol (2014) 38:1340-8. doi:10.1097/ PAS.0000000000000124

43. Russell S, Angell T, Lechner M, Liebertz D, Correa A, Sinha U, et al. Immune cell infiltration patterns and survival in head and neck squamous cell carcinoma. Head Neck Oncol (2013) 5:24.

44. Taube JM, Young GD, McMiller TL, Chen S, Salas JT, Pritchard TS, et al. Differential expression of immune-regulatory genes associated with PD-L1 display in melanoma: implications for PD-1 pathway blockade. Clin Cancer Res (2015) 21:3969-76. doi:10.1158/1078-0432.CCR-15-0244

45. Taube JM, Anders RA, Young GD, Xu H, Sharma R, McMiller TL, et al. Colocalization of inflammatory response with B7-h1 expression in human melanocytic lesions supports an adaptive resistance mechanism of immune escape. Sci Transl Med (2012) 4:127ra37. doi:10.1126/scitranslmed.3003689

46. Howitt BE, Sun HH, Roemer MGM, Kelley A, Chapuy B, Aviki E, et al. Genetic basis for PD-L1 expression in squamous cell carcinomas of the cervix and vulva. JAMA Oncol (2016) 2:518-22. doi:10.1001/jamaoncol.2015. 6326

47. Garcia-Diaz A, Shin DS, Moreno BH, Saco J, Escuin-Ordinas H, Rodriguez GA, et al. Interferon receptor signaling pathways regulating PD-L1 and PD-L2 expression. Cell Rep (2017) 19:1189-201. doi:10.1016/j.celrep.2017.04.031

48. Feng Z, Bethmann D, Kappler M, Ballesteros-Merino C, Eckert A, Bell RB, et al. Multiparametric immune profiling in HPV- oral squamous cell cancer. JCI Insight (2017) 2(14):e93652. doi:10.1172/jci.insight.93652

49. Administration USF and D. Hematology/Oncology (Cancer) Approvals \& Safety Notifications. (2017). Available from: https://www.fda.gov/Drugs/ InformationOnDrugs/ApprovedDrugs/ucm279174.htm (accessed July 14, 2017).

50. Heusinkveld M, de Vos van Steenwijk PJ, Goedemans R, Ramwadhdoebe TH, Gorter A, Welters MJP, et al. M2 macrophages induced by prostaglandin E2 and IL-6 from cervical carcinoma are switched to activated M1 macrophages by CD4+ Th1 cells. J Immunol (2011) 187:1157-65. doi:10.4049/jimmunol. 1100889

51. Sharma P, Allison JP. Immune checkpoint targeting in cancer therapy: toward combination strategies with curative potential. Cell (2015) 161:205-14. doi:10.1016/j.cell.2015.03.030

Conflict of Interest Statement: The authors declare that the research was conducted in the absence of any commercial or financial relationships that could be construed as a potential conflict of interest.

Copyright (c) 2018 Ottenhof, Djajadiningrat, Thygesen, Jakobs, Jóźwiak, Heeren, de Jong, Sanders, Horenblas and Jordanova. This is an open-access article distributed under the terms of the Creative Commons Attribution License (CC BY). The use, distribution or reproduction in other forums is permitted, provided the original author(s) and the copyright owner are credited and that the original publication in this journal is cited, in accordance with accepted academic practice. No use, distribution or reproduction is permitted which does not comply with these terms. 